\title{
PENGARUH TEKNIK PEMANGKASAN TANAMAN INDUK DAN KONSENTRASI IBA TERHADAP KEMAMPUAN PERAKARAN STEK PUCUK DAHU
}

(Dracontomelon dao)

\author{
Effect of Stock Plant Pruning and Concentration of IBA on the Root Quality of Dahu \\ (Dracontomelon dao) Shoot Cutting \\ Kurniawati P. Putri \\ Balai Penelitian Teknologi Perbenihan Bogor \\ Jl. Pakuan, Ciheuleut, Bogor \\ Telp./Fax :(0251) 8327768
}

Naskah masuk : 22 Februari 2008 ; Naskah diterima : 19 Februari 2009

\begin{abstract}
The study was aimed to evaluate the effect of pruning and application of IBA (growth hormone) on the quality of dahu (Dracontomelon dao) shoot cutting. The experimental design used in this study was Completely Randomized Design with two factors, namely height of pruning $(20 \mathrm{~cm}, 30 \mathrm{~cm}$ and $40 \mathrm{~cm})$ and concentration IBA application (0 ppm, $50 \mathrm{ppm}$ and $100 \mathrm{ppm}$ ), with three replications. The quality of dahu shoot cutting was measured based on survival rate, rooting percentage, root number, and root length. The results of analysis suggested that pruning at $40 \mathrm{~cm}$ height produced better shoot cutting quality in which survival rate and rooting percentage increased by about $10 \%$ to $15 \%$ from other cutting height. Application of IBA also increased survival rate, rooting percentage, and root number significantly.
\end{abstract}

Keywords : Dracontomelon dao, shoot cutting, pruning, growth hormone, IBA

\begin{abstract}
ABSTRAK
Tujuan penelitian adalah mengetahui pengaruh tinggi pemangkasan tanaman induk dan penggunaan konsentrasi IBA terhadap kualitas perakaran stek pucuk dahu (Dracontomelon dao). Rancangan penelitian yang digunakan adalah Rancangan Acak Lengkap Faktorial dengan dua faktor, yaitu tinggi pemangkasan tanaman induk dari atas permukaan tanah $(20 \mathrm{~cm}, 30 \mathrm{~cm}$ dan $40 \mathrm{~cm})$ dan faktor konsentrasi IBA (kontrol, $50 \mathrm{ppm}, 100 \mathrm{ppm}$ ). Pengamatan dilakukan terhadap persentase hidup, persentase berakar, jumlah akar dan panjang akar. Hasil penelitian menunjukkan bahwa sampai umur 2,5 bulan tinggi pangkasan $40 \mathrm{~cm}$ pada tanaman induk dahu menghasilkan persentase hidup $(64,44 \%)$ dan berakar $(61,11 \%)$ yang terbaik. Penambahan hormon tumbuh IBA menghasilkan persentase hidup, persentase berakar dan jumlah akar yang lebih baik dibandingkan kontrol (tanpa hormon tumbuh). Hormon tumbuh IBA 100 ppm menghasilkan persentase hidup sebesar 57,78\%, persentase berakar 60,00\% dengan 11,42 buah akar. Interaksi antara tinggi pemangkasan $40 \mathrm{~cm}$ dengan hormon tumbuh IBA $50 \mathrm{ppm}$ menghasilkan persentase berakar tertinggi yaitu sebesar $90 \%$.
\end{abstract}

Kata kunci : Dracontomelon dao, stek pucuk, pemangkasan, hormon tumbuh, IBA 


\section{PENDAHULUAN}

Dahu (Dracontomelon dao) termasuk dalam famili Anacardiaceae yang tersebar hampir di seluruh kepulauan Indonesia (Martawijaya et al., 1989). Kayunya termasuk kategori mudah dikerjakan, diplitur serta dapat dibentuk. Sifat keterawetan dan kekuatannya tergolong kelas awet III - IV dan kelas kuat II - III. Oleh karena itu jenis kayu ini banyak dimanfaatkan untuk papan, tiang balok di bawah atap, kayu lapis, venir, meubel mewah dan barang bubutan (Martawijaya et al., 1989; PROSEA, 2008). Bunga dan daunnya dapat dimasak dan dimakan sebagai sayuran atau obat tradisional, serta buahnya yang sering dimakan oleh anak-anak seperti yang banyak dilakukan di daerah Papua New Guinea (PROSEA, 2008).

Sampai saat ini untuk memenuhi kebutuhan bibit dahu masih mengandalkan pada benih. Padahal diketahui benih dahu memiliki keterbatasan dalam penyimpanan karena hanya mampu bertahan selama 3 minggu dengan kondisi viabilitas yang maksimum. Kurniaty dan Syamsuwida (2001) melaporkan bahwa benih dahu memiliki sifat benih semi rekalsitran karena mempunyai kadar air yang relatif rendah $(5 \%-14 \%)$ serta sangat peka terhadap suhu rendah $\left(15^{\circ} \mathrm{C}\right)$. PROSEA $(2008)$ menambahkan bahwa daya berkecambah benih dahu segar adalah $33 \%$, dan setelah penyimpanan selama 6 bulan benih tidak dapat berkecambah lagi. Benih berkecambah setelah 28 - 67 hari dari penaburan. Oleh karena itu penggunaan teknik perbanyakan vegetatif menjadi alternatif untuk perbanyakan dahu.

Dalam menunjang penyediaan bahan perbanyakan vegetatif secara stek diperlukan kebun pangkas yang dapat menghasilkan bahan stek. Salah satu upaya menghasilkan bahan stek yang berkualitas dan berkuantitas adalah perlakuan pemangkasan terhadap tanaman induk. Pemangkasan mampu mempertahankan sifat juvenilitas tanaman sehingga berpengaruh terhadap kualitas perakaran.

Penelitian ini bertujuan untuk mengetahui pengaruh tinggi pemangkasan tanaman induk (stock plant) dan penggunaan konsentrasi IBA terhadap kualitas perakaran stek pucuk dahu (Dracontomelon dao).

\section{BAHAN DAN METODE}

\section{A. Lokasi dan Waktu Penelitian}

Penelitian ini dilaksanakan di Stasiun Penelitian Nagrak, Bogor pada bulan Februari sampai Mei 2006.

\section{B. Bahan dan Alat}

Bahan stek yang digunakan dalam penelitian ini adalah tunas orthotrop yang diambil dari tanaman induk (stock plant) dahu umur 2 tahun yang ada di Stasiun Penelitian Nagrak, Bogor. Materi genetik dari tanaman induk dahu tersebut berasal dari Kabupaten Gowa, Propinsi Sulawesi Selatan. Selain stek dahu, bahan dan alat lainnya yang digunakan antara lain: IBA, air, fungisida, media stek (campuran tanah dan pasir), gunting stek, gergaji, cutter, ember, embrat, polybag, timbangan, label dan alat-alat tulis.

\section{Metode Penelitian}

Penelitian ini diawali dengan penanaman tanaman induk (stock plant) dahu pada tahun 2004. Setelah tanaman induk berumur 1 tahun, dilakukan pemangkasan dengan tiga macam ketinggian pemangkasan sesuai dengan perlakuan, yang dihitung dari atas permukaan tanah. Dari kegiatan pemangkasan tersebut dihasilkan tunas-tunas orthotrop sebagai bahan stek. Setelah 8 bulan dari kegiatan pemangkasan dilakukan pemanenan bahan stek dahu. Masing-masing tunas kemudian diberi label sesuai dengan perlakuan tinggi pemangkasan tanaman induknya. 
Bahan stek yang digunakan adalah bagian pucuk dengan panjang stek berkisar antara $10-15 \mathrm{~cm}$. Daun yang ada pada tunas dahu dikurangi sehingga menyisakan 2 helai, dan masing-masing daun dipotong $1 / 2$ bagian. Stek kemudian diberi hormon tumbuh IBA sesuai dengan perlakuan konsentrasi IBA. Hormon tumbuh IBA sebelumnya dilarutkan dalam aquades hingga mencapai konsentrasi $50 \mathrm{ppm}$ dan 100 ppm. Bahan stek direndam dalam larutan IBA sesuai dengan perlakuan tersebut selama 1 jam. Untuk perlakuan kontrol (IBA 0 ppm), stek dahu direndam dalam air. Bahan stek direndam dalam ember dengan posisi berdiri.

Penanaman stek dilakukan pada media tanah pasir dengan perbandingan $1: 1$ dengan posisi tegak lurus. Untuk menghindari kekeringan, maka sebelum penanaman dilakukan penyiraman terhadap media stek hingga jenuh. Pemeliharaan stek antara lain dengan penyiraman setiap pagi hari.

Pengamatan dilakukan setiap hari sampai 90 hari atau sampai terlihat stek siap dipindahkan ke persemaian (aklimatisasi). Paramater yang diamati meliputi: persentase hidup, persentase berakar, jumlah akar dan panjang akar.

Rancangan penelitian yang digunakan untuk mengetahui kernampuan perakaran stek pucuk dahu adalah Rancangan Acak Lengkap dengan pola faktorial yaitu menggunakan faktor tinggi pemangkasan tanaman induk dari atas permukaan tanah $(20 \mathrm{~cm}, 30 \mathrm{~cm}$ dan $40 \mathrm{~cm})$ dan faktor konsentrasi IBA (kontrol, 50 ppm, 100 ppm). Dalam penelitian ini digunakan ulangan sebanyak 3 dan masing-masing ulangan terdiri dari 15 stek. Analisis data yang dilakukan adalah analisis keragaman. Jika hasil analisis keragaman tersebut menunjukkan perbedaan yang nyata, maka analisa dilanjutkan dengan Uji Jarak Berganda Duncan(DMRT).

\section{HASIL DAN PEMBAHASAN}

\section{A. Hasil}

Berdasarkan hasil keragaman (Lampiran 1) diketahui bahwa perlakuan tinggi pangkasan tanaman induk memberikan pengaruh yang berbeda terhadap persentase hidup dan persentase berakar stek pucuk dahu. Sedangkan perlakuan pemberian hormon tumbuh IBA menunjukkan pengaruh yang berbeda terhadap hampir semua parameter yang diuji dalam hal ini persentase hidup, persentase berakar dan jumlah akar. Interaksi antar perlakuan yang diuji hanya berpengaruh nyata pada persentase berakar.

Kemudian berdasarkan hasil uji lanjut (Tabel 1) diketahui bahwa semakin tinggi pangkasan, maka semakin besar persentase hidup dan persentase berakar yang dihasilkan stek pucuk dahu. Tetapi pengaruh perlakuan tinggi pemangkasan tidak menunjukkan pengaruh yang berbeda terhadap parameter jumlah akar dan panjang akar.

Tabel(Table) 1. Pengaruh perlakuan tinggi pemangkasan terhadap pertumbuhan stek pucuk dahu (Effect of pruning height on growth of dahu shoot cutting)

\begin{tabular}{|c|c|c|c|c|c|}
\hline \multirow{3}{*}{$\begin{array}{l}\text { No. } \\
1 .\end{array}$} & \multirow{3}{*}{$\begin{array}{l}\text { Parameter (parameter) } \\
\text { Persentase hidup (survival rate) }\end{array}$} & \multicolumn{4}{|c|}{ Tinggi pemangkasan (pruning height) } \\
\hline & & $20 \mathrm{~cm}$ & \multicolumn{2}{|c|}{$30 \mathrm{~cm}$} & $40 \mathrm{~cm}$ \\
\hline & & $51,11 \quad a b$ & 44,44 & $\mathrm{a}$ & 64,44 \\
\hline 2. & Persentase berakar (root percentage) & $50,00 \quad a b$ & 44,44 & $\mathrm{a}$ & 61,11 \\
\hline 3. & Jumlah akar (root number) & 9,37 & 7,54 & $\mathrm{a}$ & 6,66 a \\
\hline 4. & Panjang akar (root length) & 5,61 & 5,60 & $\mathrm{a}$ & $5,40 \quad \mathrm{a}$ \\
\hline
\end{tabular}

Keterangan(Remarks): Angka-angka yang diikuti dengan huruf yang sama pada baris yang sama menunjukkan tidak berbeda nyata pada tingkat kepercayaan $95 \%$ (Values followed by the same letters in the same rows are not significantly different at $95 \%$ confidence level). 
Pengaruh perlakuan konsentrasi IBA yang diberikan terhadap stek pucuk dahu memberikan pengaruh yang sama terhadap panjang akar stek. Pengaruh yang berbeda dari konsentrasi IBA terlihat pada parameter persentase hidup, persentase berakar dan jumlah akar (Tabel 2). Interaksi antara perlakuan yang memberikan respon persentase berakar stek terbaik adalah perlakuan tinggi pemangkasan $40 \mathrm{~cm}$ yang diberi hormon tumbuh IBA dengan konsentrasi 50 ppm (Tabe13).

Tabel(Table) 2. Pengaruh perlakuan konsentrasi IBA terhadap pertumbuhan stek pucuk dahu (Effect of IBA concentration on growth of dahu shoot cutting)

\begin{tabular}{|c|c|c|c|c|c|}
\hline \multirow{3}{*}{$\begin{array}{l}\text { No. } \\
1 .\end{array}$} & \multirow{3}{*}{$\begin{array}{l}\text { Parameter (parameter) } \\
\text { Persentase hidup (survival rate) }\end{array}$} & \multicolumn{4}{|c|}{ Konsentrasi IBA (IBA concentration) } \\
\hline & & $0 \mathrm{ppm}$ & $50 \mathrm{ppm}$ & \multicolumn{2}{|c|}{$100 \mathrm{ppm}$} \\
\hline & & 38,89 & 63,33 & 57,78 & $\mathrm{~b}$ \\
\hline 2. & Persentase berakar (root percentage) & 30,00 & 65,55 & 60,00 & b \\
\hline 3. & Jumlah akar (root number) & 4,58 & 7,64 & 11,42 & $\mathrm{~b}$ \\
\hline 4. & Panjang akar (root length) & 6,67 & 5,24 & 4,69 & \\
\hline
\end{tabular}

Keterangan (Remarks) : Angka-angka yang diikuti dengan huruf yang sama pada baris yang sama menunjukkan tidak berbeda nyata pada tingkat kepercayaan $95 \%$ (Values followed by the same letters in the same rows are not significantly different at $95 \%$ confidence level)

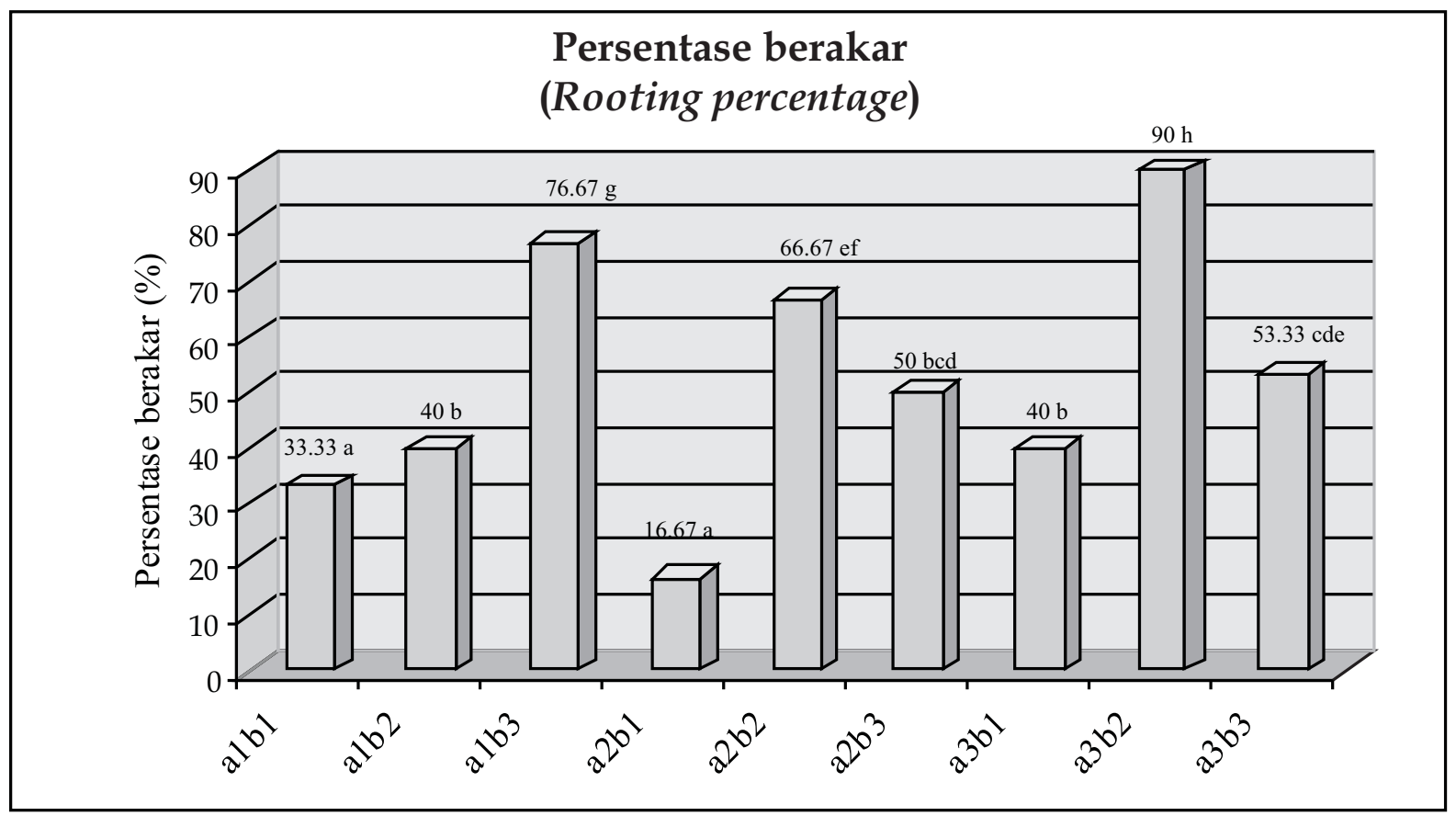

Gambar(Figure) 1. Interaksi antara tinggi pangkasan dan hormon tumbuh IBA terhadap presentase berakar stek pucuk dahu (Interaction between pruning height and concentration of IBA growth regulator on rooting percentage of dahu cutting)

Keterangan(Remarks) :

$\mathrm{a} 1 \mathrm{~b} 1=$ Tinggi pangkasan $20 \mathrm{~cm} ; \operatorname{IBA} 0 \mathrm{ppm}$ (pruning height $20 \mathrm{~cm} ; \mathrm{IBA} 0 \mathrm{ppm}$ )

alb2 = Tinggi pangkasan $20 \mathrm{~cm} ;$ IBA $50 \mathrm{ppm}$ (pruning height $20 \mathrm{~cm} ; I B A 50 \mathrm{ppm}$ )

a1b3 = Tinggi pangkasan $20 \mathrm{~cm} ;$ IBA $100 \mathrm{ppm}$ (pruning height $20 \mathrm{~cm} ; I B A 100 \mathrm{ppm}$ )

$\mathrm{a} 2 \mathrm{~b} 1=$ Tinggi pangkasan $30 \mathrm{~cm} ; \mathrm{IBA} 0 \mathrm{ppm}$ (pruning height $30 \mathrm{~cm} ; I B A 0 \mathrm{ppm}$ )

$\mathrm{a} 2 \mathrm{~b} 2=$ Tinggi pangkasan $30 \mathrm{~cm} ; \mathrm{IBA} 50 \mathrm{ppm}$ (pruning height $30 \mathrm{~cm} ; I B A 50 \mathrm{ppm}$ )

$\mathrm{a} 2 \mathrm{~b} 3=$ Tinggi pangkasan $30 \mathrm{~cm} ;$ IBA $100 \mathrm{ppm}$ (pruning height $30 \mathrm{~cm} ; I B A 100 \mathrm{ppm}$ )

$\mathrm{a} 3 \mathrm{~b} 1=$ Tinggi pangkasan $40 \mathrm{~cm} ; \mathrm{IBA} 0 \mathrm{ppm}$ (pruning height $40 \mathrm{~cm} ; \mathrm{IBA} 0 \mathrm{ppm}$ ) 
a3b2 = Tinggi pangkasan $40 \mathrm{~cm} ;$ IBA $50 \mathrm{ppm}$ (pruning height $40 \mathrm{~cm} ; \mathrm{IBA} 50 \mathrm{ppm}$ )

a3b3 = Tinggi pangkasan $40 \mathrm{~cm} ; \mathrm{IBA} 100 \mathrm{ppm}$ (pruning height $40 \mathrm{~cm} ; I B A 100 \mathrm{ppm}$ )

Angka-angka yang diikuti dengan huruf yang sama menunjukkan tidak berbeda nyata pada tingkat kepercayaan 95\% (Values followed by the same letters are not significantly different at $95 \%$ confidence level).

\section{B. Pembahasan}

Timbulnya akar merupakan indikator keberhasilan perbanyakan stek, karena akar berperan dalam pengambilan hara dalam tanah yang sangat diperlukan untuk pertumbuhan stek selanjutnya. Berdasarkan hasil penelitian diketahui bahwa respon tanaman induk (stock plant) dahu dalam bentuk persentase stek berakar terhadap tinggi pemangkasan tergantung dari besarnya konsentrasi hormon tumbuh auksin IBA yang diberikan. Kombinasi perlakuan yang memberikan persentase stek berakar tertinggi adalah tinggi pemangkasan $40 \mathrm{~cm}$ dengan penambahan hormon tumbuh auksin IBA sebesar $50 \mathrm{ppm}(90 \%)$. Hal ini menunjukkan pemangkasan dengan tinggi $40 \mathrm{~cm}$ dari atas permukaan tanah mampu mempertahankan atau mengendalikan sifat juvenilitas tanaman induk dahu, sehingga mampu untuk memunculkan akar pada steknya. Kemampuan tersebut kemudian ditunjang dengan adanya penambahan hormon tumbuh auksin IBA $50 \mathrm{ppm}$. Sehingga kombinasi keduanya mampu menghasilkan persentase stek berakar yang tertinggi, sebagaimana diketahui bahwa pemangkasan merupakan salah satu teknik rejuvenasi yang bertujuan untuk mendapatkan bahan vegetatif tanaman yang secara fisiologis bersifat muda (juvenil). Hartman et al. (1990) menyatakan bahwa rejuvenasi tanaman adalah suatu perubahan fase, dari fase jaringan tanaman tua menjadi fase yang menghasilkan jaringan muda (juvenil) selama pertumbahan vegetatif berlangsung. Bagian tanaman yang bersifat juvenil tersebut dibangun oleh jaringan-jaringan muda sehingga sangat mudah untuk merangsang keluarnya akar (Haisig dalam Aminah, 2001). Kijkar (1991) menambahkan bahwa pemangkasan tanaman induk (stock plant) selain bertujuan untuk meningkatkan produksi tunas sebagai sumber bahan stek, juga untuk mempertahankan atau mengendalikan sifat juvenilitas sehingga mampu meningkatkan kemampuan perakaran steknya. Upaya lainnya yang biasa dilakukan untuk merangsang pertumbuhan akar pada stek adalah dengan penambahan hormon tumbuh auksin seperti IBA. Seperti yang dinyatakan Hartman et al. (1990) yaitu pemberian hormon tumbuh dapat mempercepat pembentukan akar, meningkatkan jumlah akar, serta meningkatkan keseragaman pertumbuhan akar.

Pemangkasan tanaman induk (stock plant) dahu setinggi $40 \mathrm{~cm}$ dari atas permukaan tanah menghasilkan stek dengan persentase hidup $(64,44 \%)$ yang lebih besar dibandingkan pemangkasan pada ketinggian $20 \mathrm{~cm}(51,11 \%)$ dan $30 \mathrm{~cm}(44,44 \%)$. Perbedaan persentase hidup tersebut secara tidak langsung berhubungan dengan tingkat juvenilitas tanaman yang disebabkan kegiatan pemangkasan. Persentase berakar dari stek yang berasal dari hasil pemangkasan $40 \mathrm{~cm}$ lebih baik dibandingkan dengan tinggi pemangkasan lainnya. Hal ini diduga karena proses pembentukan akarnya terjadi lebih cepat, sehingga proses penyerapan unsur hara dari dalam tanah dapat berlangsung dengan baik. Jika akar belum terbentuk dengan sempurna, maka stek akan mati karena cadangan makanan yang tersimpan dalam bahan stek telah habis digunakan dalam proses sebelumnya. Semakin cepat perakaran stek terbentuk, semakin besar tingkat keberhasilan penyetekan tersebut. Dalam hal ini kemampuan berakar dari stek yang berasal dari hasil pemangkasan $40 \mathrm{~cm}$ lebih baik dibandingkan dengan tinggi pemangkasan lainnya, sehingga persentase hidup steknya juga lebih tinggi.

Dalam penelitian ini persentase hidup stek pucuk dahu juga dipengaruhi oleh besarnya kandungan hormon tumbuh. Stek pucuk dahu yang menunjukkan persentase hidup tertinggi $(63,33 \%$ dan 57,78 \%) adalah stek yang diberi tambahan hormon tumbuh IBA (50 ppm dan $100 \mathrm{ppm})$ dan persentase hidup terendah $(38,89 \%)$ dihasilkan oleh stek yang tidak diberi hormon tumbuh IBA. Kondisi tersebut menandakan bahwa kemampuan hidup stek yang diberi tambahan zat pengatur tumbuh (50 ppm dan $100 \mathrm{ppm}$ ) adalah lebih baik dibandingkan dengan stek yang tidak diberi tambahan zat pengatur tumbuh. 
Pemangkasan setinggi $40 \mathrm{~cm}$ dapat meningkatkan persentase hidup dan berakar stek pucuk dahu sebesar $10 \%$ dan $15 \%$ dibandingkan tinggi pemangkasan lainnya. Namun tidak demikian responnya terhadap peningkatan jumlah dan panjang akar. Ketiga macam tinggi pemangkasan $(20 \mathrm{~cm}$, $30 \mathrm{~cm}$ dan $40 \mathrm{~cm}$ ) tersebut menghasilkan jumlah dan panjang akar yang relatif sama. Rata-rata jumlah dan panjang akar yang dihasilkan masing-masing sebesar 7,86 buah dan 5,54 cm. Hal ini menandakan bahwa teknik pemangkasan yang digunakan dalam penelitian ini belum berperan banyak dalam upaya meningkatkan kualitas perakaran stek dahu yang dihasilkan dalam hal ini jumlah dan panjang akar. Padahal teknik pemangkasan yang tepat tentunya yang mampu mengoptimalkan kualitas sistem perakaran stek. Seperti yang telah terbukti pada jenis Khaya senegalensis dimana tinggi pemangkasan 30 cm mampu meningkatan kualitas perakaran steknya (Limpiyaprapat et al., 1996 dalam Pramono et al., 2001).

Kualitas perakaran stek seperti jumlah dan panjang akar dapat ditingkatkan dengan pemberian hormon tumbuh auksin. Hormon tumbuh auksin berperan dalam meningkatkan kecepatan transportasi dan gerakan karbohidrat ke dasar stek yang secara tidak langsung berpengaruh terhadap pertumbuhan dan perkembangan akar. Walaupun demikian setiap jenis tanaman mempunyai tingkat konsentrasi optimum yang berbeda yang dapat memaksimalkan proses differensiasi sel. Wareing dan Philips (1970) dalam Adinugraha et al. (2006) menyatakan bahwa auksin pada konsentrasi yang optimum sangat berperan aktif dalam proses differensiasi sel, namun pada konsentrasi di atas optimum auksin dapat bersifat racun yang dapat menurunkan hasil yang diinginkan. Dalam penelitian ini diketahui bahwa aplikasi hormon tumbuh IBA dengan konsentrasi 100 ppm menghasilkan jumlah akar terbanyak yaitu 11,42 buah, walaupun tidak berbeda nyata dengan stek yang diberi IBA 100 ppm (7,62 buah). Untuk parameter panjang akar, konsentrasi IBA yang diberikan pada stek dahu ternyata belum menunjukkan responnya terhadap panjang akar. Karena panjang akar stek yang dihasilkan relatif sama dengan panjang akar stek yang tidak diberi hormon tumbuh IBA. Rata-rata panjang akar stek dahu adalah $5,53 \mathrm{~cm}$. Diduga pemberian IBA $50 \mathrm{ppm}$ dan $100 \mathrm{ppm}$ hanya mampu merangsang keluarnya akar, tetapi belum mampu meningkatkan panjang akar yang dihasilkannya tersebut. Weaver 1972 dalam Siregar (2003) menyebutkan bahwa hormon tumbuh IBA yang diberikan pada stek hanya berperan dalam mempercepat pertumbuhan akar dan tunas saja, karena proses perkembangan akar selanjutnya lebih banyak dipengaruhi oleh karbohidrat cadangan atau karbohidrat hasil fotosintesa.

\section{KESIMPULAN}

1. Pemangkasan setinggi $40 \mathrm{~cm}$ menghasilkan persentase hidup stek pucuk dahu yang lebih baik dibandingkan dengan pemangkasan setinggi $20 \mathrm{~cm}$ dan $30 \mathrm{~cm}$.

2. Pemangkasan setinggi $20 \mathrm{~cm}, 30 \mathrm{~cm}$, dan $40 \mathrm{~cm}$ belum mampu meningkatkan kualitas (jumlah dan panjang) akar stek pucuk dahu.

3. Penambahan hormon tumbuh IBA mampu meningkatkan persentase hidup, persentase berakar, dan jumlah akar stek pucuk dahu.

4. Berdasarkan nilai persentase berakarnya, pemangkasan setinggi $40 \%$ akan efektif dalam meningkatkan persentase berakar jika dikombinasikan dengan penambahan hormone tumbuh IBA $50 \mathrm{ppm}$. 


\section{DAFTAR PUSTAKA}

Adinugraha, H. A., H. Moko dan Cepi. 2006. Pertumbuhan Stek Pucuk Sukun Asal dari Populasi Nusa Tenggara Barat dengan Aplikasi Zat Pengatur Tumbuh. Jurnal Penelitian Hutan tanaman Vol 3 (2): 93 - 100, Yogyakarta.

Aminah. 2001. Vegetative Propagation of Endospermum malacense by Leavy Steam Cutting : Effect of IBA Concentration and Propagation System (mist and non mist). Journal of Tropical Forest Science $15(2): 249-258$.

Hartman, H. T., D.E. Kester, and F. T. Davies. 1990. Plant Propagation Principles and Practices. Fifth Edition. Prentice Hall Inc, Englewood Cliffs, New Jersey.

Kijkar, S. 1991. Production of Rooted Cuttings of Eucalyptus camaldulensis. Hand Book. ASEN-Canada. Forest Tree Seed Centre Project. Muak-Lek, Saraburi 1810, Thailand.

Kurniaty, R. dan D. Syamsuwida. 2001. Penyimpanan Benih Dahu (Dracontomelon dao). Buletin Teknologi Perbenihan 8(1): 110 - 118. Balai Teknologi Perbenihan, Bogor.

Martawijaya, A., L. Kartasujana, K. Kadir, dan S. A. Prawira. 1989. Atlas Kayu Indonesia Jilid II, Badan Penelitian dan Pengembangan Kehutanan, Bogor.

Pramono, A.A., A.Z. Abidin dan A. Rachmat. 2001. Meningkatkan Perolehan Tunas Berkualitas pada Kebun Pangkas. Tekno Benih VI (1) : 56-62. Balai Teknologi Perbenihan, Bogor.

PROSEA. 2008. Dracontomelon dao : Species identity in a Tree Species Reference and Selection Guide. Diakses pada tanggal 3 Februari 2009. http://www.worldagroforestry.org/sea/Products/ AFDbases/AF/asp/SpeciesInfo.asp? SpID=1792.

Siregar, N. W. 2003. Pengaruh Tingkat Kerapatan Naungan dan Konsentrasi Zat Pengatur Tumbuh IBA terhadap Pertumbuhan Stek Damar Mata Kucing (Shorea javanica $K \&$ V). Buletin Hutan Tanaman 1(1) : 8- 22. Balai Penelitian Hutan Tanaman Palembang. 
Lampiran (Appendix) 1. Analisis keragaman pengaruh tinggi pemangkasan dan hormon IBA terhadap persentase hidup, persentase berakar, jumlah akar dan panjang akar pucuk dahu (Analysis of variance on effect of pruning height and IBA concentration growth regulator on survival rate, root percentage, root number and root length of dahu shootcutting)

\begin{tabular}{|c|c|c|c|c|c|}
\hline $\begin{array}{c}\text { Parameter } \\
\text { (Parameters) }\end{array}$ & $\begin{array}{l}\text { Sumber Keragaman } \\
\text { (Source of variation) }\end{array}$ & $\begin{array}{l}\text { Derajat bebas } \\
\text { (Degrees of } \\
\text { freedom) }\end{array}$ & $\begin{array}{l}\text { Jumlah kuadrat } \\
\text { (Sum of } \\
\text { squares) }\end{array}$ & $\begin{array}{l}\text { Kuadrat } \\
\text { tengah } \\
\text { (Mean } \\
\text { square) }\end{array}$ & $\begin{array}{l}F_{\text {nitung }} \\
\left(F_{\text {value }}\right)\end{array}$ \\
\hline $\begin{array}{l}\text { Persentase } \\
\text { hidup } \\
\text { (Survival } \\
\text { percentage) }\end{array}$ & $\begin{array}{l}\text { Tinggi pangkasan (height) } \\
\text { Hormon (hormone) } \\
\text { Interaksi (interaction) } \\
\text { Galat (error) } \\
\text { Total (Total) }\end{array}$ & $\begin{array}{r}2 \\
2 \\
4 \\
18 \\
26\end{array}$ & $\begin{array}{r}1866,667 \\
2955,556 \\
1311,111 \\
4666,667 \\
10800,001\end{array}$ & $\begin{array}{r}933,333 \\
1477,778 \\
327,778 \\
259,259\end{array}$ & $\begin{array}{l}3,6 * \\
5,7 * \\
1,3 \text { tn }\end{array}$ \\
\hline $\begin{array}{l}\text { Persentase } \\
\text { berakar (Root } \\
\text { percentage) }\end{array}$ & $\begin{array}{l}\text { Tinggi pangkasan (height) } \\
\text { Hormon (hormone) } \\
\text { Interaksi (interaction) } \\
\text { Galat (error) } \\
\text { Total (Total) }\end{array}$ & $\begin{array}{r}2 \\
2 \\
4 \\
18 \\
26\end{array}$ & $\begin{array}{r}1296,296 \\
6585,185 \\
4592,593 \\
2533,33 \\
15007,407\end{array}$ & $\begin{array}{r}648,148 \\
3292,593 \\
1148,148 \\
140,741\end{array}$ & $\begin{array}{r}4,6 * \\
23,4 * \\
8,2 *\end{array}$ \\
\hline $\begin{array}{l}\text { Jumlah akar } \\
\text { (Root } \\
\text { number) }\end{array}$ & $\begin{array}{l}\text { Tinggi pangkasan (height) } \\
\text { Hormon (hormone) } \\
\text { Interaksi (interaction) } \\
\text { Galat (error) } \\
\text { Total (Total) }\end{array}$ & $\begin{array}{r}2 \\
2 \\
4 \\
18 \\
26\end{array}$ & $\begin{array}{r}33,073 \\
211,482 \\
55,426 \\
250,100 \\
550,081\end{array}$ & $\begin{array}{r}16,536 \\
105,741 \\
13,857 \\
13,894\end{array}$ & $\begin{array}{l}1,2 \text { tn } \\
7,6^{*} \\
1,0 \text { tn }\end{array}$ \\
\hline $\begin{array}{l}\text { Panjang akar } \\
\text { (Root length) }\end{array}$ & $\begin{array}{l}\text { Tinggi pangkasan (height) } \\
\text { Hormon (hormone) } \\
\text { Interaksi (interaction) } \\
\text { Galat (error) } \\
\text { Total (Total) }\end{array}$ & $\begin{array}{r}2 \\
2 \\
4 \\
18 \\
26\end{array}$ & $\begin{array}{r}0,810 \\
10,728 \\
6,541 \\
46,490 \\
64,569\end{array}$ & $\begin{array}{l}0,405 \\
5,364 \\
1,635 \\
2,583\end{array}$ & $\begin{array}{l}0,2 \text { tn } \\
2,1 \text { tn } \\
0,6 \text { tn }\end{array}$ \\
\hline
\end{tabular}

Keterangan(Remarks): * = Berbeda nyata pada selang kepercayaan $95 \%$ (Signiftcantly different at $95 \%$ confidence level) $\mathrm{tn}=$ Tidak berbeda nyata (Not significantly different) 